\title{
Assessing reported condom use among female sex workers in southern India through examination of condom availability
}

\author{
Janet Bradley, ${ }^{1}$ Stephen Moses, ${ }^{2,3}$ James F Blanchard, ${ }^{2,3}$ S Rajaram, ${ }^{1}$ B M Ramesh, ${ }^{2}$ \\ Supriya Verma, ${ }^{1}$ Michel Alary ${ }^{4}$
}

${ }^{1}$ CHARME-India Project, Bangalore, India ${ }^{2}$ University of Manitoba, Winnipeg, Canada ${ }^{3}$ Karnataka Health Promotion Trust, Bangalore, India ${ }^{4}$ Centre Hospitalier Affilié Universitaire de Québec, Québec, Canada

\section{Correspondence to}

J Bradley, KHPT office, IT/BT Park 4th and 5th Floor, \#1-4, Rajajinagar Industrial Area, Behind KSSIDC Administrative Office, Rajajinagar, Bangalore, India 560 044; jbradley@uresp. ulaval.ca

Accepted 18 November 2009

\section{ABSTRACT}

Objectives A key indicator of success of HIV prevention programmes is the number of female sex worker (FSW) sex acts protected by condoms. This measure usually relies on FSW reports, which may be biased. We examined condom availability data in five Karnataka districts to estimate the proportion of FSW sex acts potentially protected by condoms.

Methods Financial, programme, population, condom and contraceptive data were obtained from governmental and non-governmental sources, surveys and HIV prevention programmes. Sexual behaviour data were obtained from general population and FSW surveys. We examined four scenarios in a sensitivity analysis, each one assuming different proportions of available condoms that might have been used by sex workers.

Results Possible condom use rates for all FSW sex acts ranged from $3 \%-36 \%$ in 2004 to $56 \%-96 \%$ in 2008 . The two most realistic scenarios that discounted the number of private sector condoms that might have been bought for sex acts other than with FSWs showed that 16-24\% of FSW sex acts could have been protected by condoms in 2004 rising to $77-85 \%$ in 2008.

Conclusions These data suggest that condom availability in these Karnataka districts in 2004 was low in relation to the number of FSW sex acts, but rose substantially over the ensuing 4 years. Condom availability data can be useful for triangulation with other available data, such as self-reported condom use, to provide a range of possibilities regarding the number of FSW sex acts protected by condoms.

\section{INTRODUCTION}

The HIV epidemic in southern India is thought to be a concentrated epidemic, driven to a large extent by heterosexual sex between female sex workers (FSWs) and their male partners, who then transmit infection to their spouses and other partners. ${ }^{1-3}$ The Bill \& Melinda Gates Foundation launched the India AIDS Initiative (Avahan) in Karnataka and five other states in 2004 to scale-up targeted HIV preventive intervention programmes (TIs) for key populations most at risk of acquiring and transmitting HIV, particularly FSWs and men who have sex with men. ${ }^{4-6}$ In Karnataka, the Avahan state implementing agency is the Karnataka Health Promotion Trust (KHPT).

One of the key output indicators to monitor the success of TI activities is the proportion of FSWs over time who use condoms with their clients and other sexual partners. ${ }^{4}$ Condom use estimates for the most part rely on information reported by FSWs themselves in cross-sectional surveys, termed integrated behavioural and biological assessments (IBBAs), and other surveys. However, these data have two main drawbacks. First, it is difficult to ascertain a true baseline rate for reported condom use since information on sexual risk-taking often cannot be obtained from FSWs until well after programme initiation, when trust from within the community has been secured. Second, social desirability bias may be pronounced, as data are collected in contexts that include strong educational campaigns and other norm-setting activities. ${ }^{7-9}$

One way of validating self-reported condom use is to assess condom availability and compare the number of reported FSW sex acts with the total number of available condoms (discounting those used by the general population). However, few studies have been able to use condom availability to corroborate rates of condom use because both condom supply data and potential demand estimates (that include sex worker and general population needs for infection and pregnancy prevention) are not widely available. ${ }^{10}$

In Karnataka, both private sector point of sale condom data and TI programme condom data are available, as well as IBBA data from five districts regarding FSW sex acts with both paying clients and other sexual partners. In this paper, we examine four different scenarios to estimate condom availability to FSWs over time in the urban areas of the five Karnataka districts where IBBAs have been conducted (Shimoga, Belgaum, Bellary, Mysore and Bangalore). These condom data are then compared to the total number of reported FSW sex acts where condoms could be utilised.

\section{METHODS}

\section{Data sources}

Financial and programme data were obtained from KHPT and from the Karnataka State AIDS Prevention Society (KSAPS) for 2004-2008. Population and contraceptive data were obtained from the Indian national census ${ }^{11}$ and the third National Family Health Survey. ${ }^{12}$ Point-of-sale private sector condom sales data were supplied by Population Services International (PSI), which purchases the data from a private sector marketing company. Private sector sales data are available from 2005-2008, and are disaggregated at the level of urban/rural for each state in the country. The TI programmes also supply government condoms unlocked scheme, see http://sti. bmi.com/site/about/unlocked. xhtml. 
procured specifically for FSWs. Most of these are distributed directly to FSWs through a system of peer educators, and others are picked up by sex workers in the programme drop-in centres or from drop boxes. The TI programme also includes condoms that are socially marketed by PSI. KHPT has a comprehensive computerised management information system and tracks all condoms distributed by over 400 peer educators in the five districts, who directly distribute $90 \%$ of free programme condoms. In this paper, we distinguish between the private sector condoms (PSCs) that are for purchase in the marketplace by the general community and TI programme condoms (that include the PSI socially marketed condoms) (TICs) that are targeted to FSWs. The FSW TI programme in Bangalore urban area is shared between KHPT and KSAPS and so for Bangalore we have included TICs that are distributed by both programmes. In the other four districts, the only TIs are those managed by KHPT.

FSW IBBA surveys include a sample of 400 FSWs per district, selected through a two-stage cluster sampling using a probability proportional to size method and simple random sampling at the second stage. ${ }^{13} 14$ We used data from the IBBA FSW second round surveys (conducted between 2006-2009) to estimate, for each district, the number of FSW sex acts with all types of partners that could potentially be protected by a condom. Data are available for spouses/cohabiting partners and other noncommercial partners (number of sex acts per week), and for paying clients (number of clients per week). ${ }^{15}$ We used district FSW size estimates from 2007 supplied by KHPT. ${ }^{16}$ Information on how these size estimates were calculated are described elsewhere. $^{17}$

Data on sexual behaviour in the general population were obtained from three Karnataka general population surveys conducted in Mysore, Belgaum and Bellary. ${ }^{18-20}$

\section{Estimation procedures Condoms}

To calculate the number of condoms potentially available for FSW sex acts, we summed both those condoms sold in the commercial sector (PSCs) with those available through the KHPT and KSAPS TICs. We excluded condoms that are sent by the Karnataka state government's Department of Health and Family Welfare to district medical offices, and from there to health centre and hospital clinics, as these are largely inaccessible to sex workers and male clients, as they are mainly available in family planning clinics, where neither sex workers nor clients feel comfortable in approaching staff for condoms. To estimate the number of PSCs sold in the five IBBA districts, we calculated the number of people aged 15-49 years in the 28 towns where the five IBBAs were carried out as a proportion of all urban areas in Karnataka (47\%). We then assumed that $47 \%$ of all condoms sold in urban areas in Karnataka in the years 2005-2008 were sold in the urban areas of the five IBBA districts. For 2004, we assumed the same commercial sales as in 2005. For each district, we assumed that the purchases would be proportional to the size of their sexually active populations. So, for example, we estimated that of all the PSCs sold in the five IBBA districts, $68.4 \%$ would be sold in Bangalore.

All PSCs and TICs condoms were summed. Other estimates from India ${ }^{21}$ suggest that $30 \%$ of distributed condoms are 'wasted' (lost, expired, not used, spoiled or torn). Because the Karnataka programmes are well-managed, with condoms mostly being directly distributed to those who ask for them, we assumed wastage would be somewhat less, and indeed KHPT uses a figure of $15 \%$ wastage for its programmes. We also know that there is a considerable amount of double condom use that KHPT may not have fully incorporated in its estimates. ${ }^{22}$ Adding this to other forms of wastage, we estimated $20 \%$ wastage overall.

\section{Sex acts}

We assumed that each client had only one sex act with an FSW at any given sexual encounter. District-wise urban FSW size estimates were used to calculate the annual mean number of sex acts by FSWs per district with both clients and other sexual partners and, although masking some heterogeneity, these were summed to estimate the total number of such sex acts per year in the five IBBA districts. We assumed that this number was constant over the years of the analysis. It was also possible to estimate the mean number of condoms used per year per sex worker for each district and to compare this to the mean number of total sex acts.

\section{Sensitivity analysis}

We examined four scenarios in a sensitivity analysis. In scenario 1 , it was assumed that all available condoms in the five IBBA areas, both PSCs and TICs, were used for FSW sex acts and no other reason. This obviously overestimates the numbers of condoms used for FSW sex acts and serves as an upper bound.

In scenario 2 , we subtracted from the total number of PSCs those that might be purchased by the general population for family planning. The 2005-2006 National Family Health Survey, round $3,{ }^{12}$ found that $63 \%$ of Karnataka urban dwellers in the 15-49-years age group were sexually active and that $4.8 \%$ of urban men reported using condoms for family planning. Of these, $82 \%$ reported that they used a commercial or private source of supply. In general population surveys that we have conducted in Mysore, Bellary and Belgaum, the majority of sexually active married men reported that they had sex with their wives once to twice per week. ${ }^{18-20}$ Therefore, we assumed that those using condoms for family planning would use 52 condoms per year. We assumed that this rate of commercial condom use for family planning by married men remained constant over the years of the analysis and that wastage would again be $20 \%$ of the total. Thus, the number of PSCs likely used for family planning was subtracted from the total number of PSCs to estimate the number of PSCs that could have been bought by men or FSWs for sex between them.

In scenario 3, we also discounted PSCs bought for sex in the general population by applying a different measure. Scenario 2 does not take into account condoms that might be used by married or unmarried men for non-FSW sex-for example, with girlfriends and lovers, and not construed as being used for family planning alone. Estimates of sex outside marriage are difficult to ascertain, although 'polling booth'surveys (PBSs) in Karnataka suggest that it is higher than that admitted in face-to-face interviews. ${ }^{18-20}$ In a PBS in Belgaum, $33 \%$ of married urban men admitted to ever having sex with someone other than a spouse or FSW (8.5\% in the previous year). Among unmarried men, 19\% admitted that they had ever had sex ( $8.0 \%$ in the previous year), and more than one-third of them reported using a condom at last sex. ${ }^{18}$ Figures for Bangalore, a modern cosmopolitan city, are likely higher. To estimate possible condom use by such men, we used data from the Mysore general population survey ${ }^{20}$ that showed that $8.0 \%$ of sexually active men used a condom at last sex as a proxy for condom use for family planning in marriage, plus protection against pregnancy and STIs in other relationships by married and unmarried men. We assumed as before that such men who used a condom at last sex would use condoms 52 times per year and that wastage would again be $20 \%$ of the total. Thus, the number of condoms possibly bought for all family planning 
and other non-FSW sex acts in the general population was subtracted from the total number of PSCs sold to estimate the number potentially used for FSW sex acts.

Finally, in scenario 4 we assumed that none of the PSCs were bought by sex workers or their clients for FSW sex, and that only TICs were available to them. This then underestimates the numbers of condoms used in FSW sex and represents a lower bound.

\section{RESULTS}

PSCs in the five IBBA district urban areas increased from an estimated 8.8 million to 10.8 million (18\%) between 2004-2008, which, after accounting for $20 \%$ wastage, we estimated resulted in between 7.0 and 8.7 million condoms sold. In contrast, between 2004-2008, the number of TICs increased from 801000 to 15.2 million or, after discounting for wastage, 641000 to 12.1 million (table 1), of which almost 7 million were distributed/ socially marketed in Bangalore.

The KHPT size estimates for the urban areas of the five IBBA districts show that there are over 33600 FSWs, with approximately 24300 of this number in Bangalore. In total, we estimated that urban sex workers in the five districts have about 21.6 million sex acts per year, 19.1 million of which are with paying clients, and almost 14 million of which take place in Bangalore (table 2). The estimated annual mean number of sex acts per FSW in the five districts was 644, with the highest being Bellary at 1068 and the lowest in Mysore at 536. In 2003, before the Avahan programme began, the only significant source of condoms for FSWs and their clients would have been the private sector. After that time, if only programme condoms were used by sex workers, we estimated that the mean annual number of condoms per sex worker per district increased from virtually nil in 2004, to between 282 and 670 in 2008 (figure 1). By 2008, programme condoms alone, after wastage, could potentially have covered between 49\% (Bangalore) and 95\% (Shimoga) of all FSW sex acts.

In order to estimate what proportion of sex acts could potentially have been covered by condoms in all five districts between 2004 and 2008, we included potential private sector purchases in the four possible scenarios described above. In the first scenario, the upper limits of use, where it is assumed that all available condoms in the five districts (7.7 million in 2004 and
20.8 million in 2008) were utilised for FSW sex alone (ie, none for family planning or other purposes), the proportion of FSW sex acts covered would have been $35.6 \%$ in 2004 and $96.1 \%$ in 2008 (table 3). In scenario 4, the lower bound of use, where no condoms are bought by sex workers or their partners, and only programme condoms are utilised, $3.0 \%$ of FSW sex acts would have been covered by condoms in 2004 and $56.1 \%$ in 2008. The other two scenarios that discount the number of purchased condoms that might have been bought by individuals for FSW sex show more realistic estimates of the proportion of sex acts that could have been protected by condoms. In scenarios 3 and 2 , $16-24 \%$ of all FSW sex acts would have been protected by condoms in 2004 , rising to $77-85 \%$ in 2008 .

\section{DISCUSSION}

It has proven difficult in many settings to estimate the number of potentially protected FSW sex acts through examination of condom availability. First, condom data are needed from various sectors; while sex worker intervention programmes may have these data, figures from the private sector are often difficult to obtain and, where they are available, may only reflect the numbers sold by primary manufacturers to warehousing companies or stores ${ }^{10}$ and not actual sales to customers. Thus, these data include over-supply, returns, expiries and wastage at the warehousing or shop level. Another major constraint is that public sector (and NGO) condom data usually reflect the number distributed and not the numbers actually used. Particularly in poorly managed programmes, there may be considerable oversupply, dumping or wastage. One study from India estimates that this may account for more than one-third of all condoms distributed. ${ }^{21}$ Regarding potential demand (number of sex acts), not all programmes collect detailed data from FSWs on the number of clients, frequency of sex with different types of clients and with non-commercial partners, and the number of sex acts.

As far as we are aware, this is the first time that comprehensive targeted intervention programme condom distribution data, socially marketed condom data and private sector condom sales data, coupled with detailed estimates of sexual activity, have been used to estimate possible FSW condom use rates. A key finding of this analysis is that condom use in 2004, before the start of the Avahan programme, must of necessity have been

Table 1 Condoms available in each district by per year and by source

\begin{tabular}{|c|c|c|c|c|c|c|}
\hline District & Condoms available & 2004 & 2005 & 2006 & 2007 & 2008 \\
\hline \multirow[t]{3}{*}{ Shimoga } & Targeted intervention condoms & 40000 & 135737 & 373209 & 688383 & 905401 \\
\hline & Private sector condoms sold & 483962 & 483962 & 447444 & 513778 & 593712 \\
\hline & Total condoms & 523962 & 619699 & 820653 & 1202161 & 1499113 \\
\hline \multirow{2}{*}{ Belgaum } & Private sector condoms sold & 612216 & 612216 & 566020 & 649932 & 751050 \\
\hline & Total condoms & 812216 & 949876 & 1500908 & 1857260 & 2091996 \\
\hline Bellary & Targeted intervention condoms & 48000 & 162274 & 1054489 & 2106342 & 2118419 \\
\hline \multirow[t]{3}{*}{ Mysore } & Targeted intervention condoms & 0 & 254386 & 634825 & 1017938 & 938057 \\
\hline & Private sector condoms sold & 632764 & 632764 & 585018 & 671747 & 776259 \\
\hline & Total condoms & 632764 & 887151 & 1219843 & 1689686 & 1714316 \\
\hline \multirow[t]{2}{*}{ Bangalore } & Targeted intervention condoms & 353184 & 380451 & 2723340 & 5910866 & 6853756 \\
\hline & Private sector condoms sold & 4850958 & 4850958 & 4484920 & 5149812 & 5951027 \\
\hline
\end{tabular}

Numbers shown reflect calculations after discounting for $20 \%$ wastage. 
Table 2 Estimated number of female sex worker (FSW) sex acts per district per year

\begin{tabular}{lcclrc}
\hline District & $\begin{array}{l}\text { Number } \\
\text { of FSWs }\end{array}$ & $\begin{array}{l}\text { Paying client } \\
\text { sex acts }\end{array}$ & $\begin{array}{l}\text { Other non- } \\
\text { commercial } \\
\text { sex acts }\end{array}$ & $\begin{array}{l}\text { Total sex } \\
\text { acts }\end{array}$ & $\begin{array}{l}\text { Mean number } \\
\text { of sex acts per } \\
\text { FSW per year }\end{array}$ \\
\hline Shimoga & 1587 & 836538 & 121119 & 958656 & 603 \\
Belgaum & 2000 & 1611353 & 100744 & 1712097 & 856 \\
Bellary & 3852 & 3866336 & 249451 & 4115787 & 1068 \\
Mysore & 1950 & 932316 & 111995 & 1044311 & 536 \\
Bangalore & 24301 & 11878329 & 1976225 & 13854554 & 570 \\
Total & 33690 & 19124871 & 2559534 & 21684405 & 644 \\
\hline
\end{tabular}

very low. Even if all available condoms in the five districts were utilised for FSW sex acts, a very unlikely proposition, no more than $36 \%$ of FSW sex acts could have been protected. If only TI programme-distributed condoms were used, then as few as $3 \%$ of acts would have been protected. Clearly the truth lies somewhere in between: with intimate knowledge of the study areas, the sex worker TI programmes and their reach, we feel that scenarios 2 or 3 would be more accurate representations of reality. By 2008, we estimate that between $77-85 \%$ of all FSW sex acts were protected by condoms.

There is no real 'gold standard' for validating self-reported sexual behaviour, ${ }^{23}$ and sex worker reporting of condom use is clearly subject to social desirability bias. The extent of this bias is unknown, although studies using more anonymous interviewing techniques, such as polling booth surveys, suggest that face-toface interviews may overestimate condom use by as much as $8-20$ percentage points. ${ }^{724}$ Certainly, reported condom use varies substantially, depending on the nature of the questions asked, ${ }^{10}$ and condom use reported by FSWs often differs substantially (and can be significantly higher) than that reported by their clients. ${ }^{25}$ Our data question the validity of information provided by sex workers interviewed early in the Avahan programme in Karnataka, who often reported that most sex acts were protected. In the five Karnataka IBBA districts, very few FSW acts could have been protected in 2004 as there simply were too few condoms available: a fact corroborated by KHPT field workers. Four to five years into the programme, with substantial increases in the numbers of condoms distributed and sold, it can be seen that the majority of FSW sex acts were potentially protected by 2008.

Of interest also is that the number of purchased PSCs increased slightly over time, which may reflect more male clients buying condoms for sex with sex workers. It is also possible that with increased awareness of HIV, more low-risk men began using condoms with their low-risk partners. It could also reflect a rapidly growing young and more sexually active urban middle class in Bangalore over the past few years. It seems unlikely that many

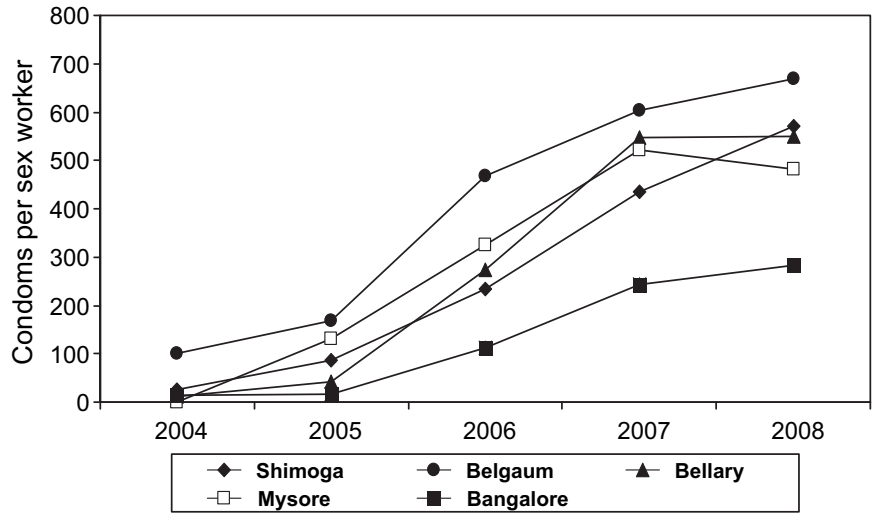

Figure 1 Number of targeted intervention programme condoms per female sex worker, per district, per year, through direct programme distribution or social marketing, 2004-2008. This slide represents the number of condoms available from targeted HIV preventive intervention programmes programmes divided by the number of sex workers estimated to be in the urban areas of the districts. Data from Karnataka Health Promotion Trust and Karnataka State AIDS Prevention Society management information systems.

men would buy condoms for commercial sex once they are freely available to the sex workers, although there is anecdotal evidence that some men prefer commercially available condoms, especially since the arrival of more attractive brands than those provided by government to the TI programmes. Some may argue that free condoms merely replace those that would otherwise be purchased, although others contend that provision of free condoms remains an essential component of public health programming as sex workers and their clients may not consistently purchase condoms for all acts at all times. ${ }^{26}$ In this analysis, it seems that the small increase over time in purchased PSCs would be able to meet nowhere near the actual condom need, as suggested by the numbers of sex acts reported by FSWs.

The study has several limitations. For some parameters, we had to use sex worker reports; for example, for the weekly number of sex acts, which, because of social desirability bias, may underestimate actual sexual activity. On the other hand, we assumed that FSWs were sexually active all year, which may be an overestimate; thus, compensating for the under-reporting of weekly events. We also had to use a one time-point assessment of sex acts in each district, and assumed no change over time, which may not be the case. Furthermore, we had to use size estimates that may under-count the actual number of women selling sex in each district, although the most recent estimates (2007) are certainly more robust than earlier estimates.

Table 3 Percentage of all female sex worker (FSW) sex acts potentially covered by condoms under four different scenarios, in five IBBA districts, 2004-2008

\begin{tabular}{|c|c|c|c|c|c|c|c|c|c|c|}
\hline \multirow[b]{2}{*}{ Scenario } & \multicolumn{2}{|l|}{2004} & \multicolumn{2}{|l|}{2005} & \multicolumn{2}{|l|}{2006} & \multicolumn{2}{|l|}{2007} & \multicolumn{2}{|l|}{2008} \\
\hline & $\begin{array}{l}\text { Condoms } \\
\text { potentially } \\
\text { available } \\
\text { (millions) }\end{array}$ & $\begin{array}{l}\% \text { of all } \\
\text { FSW sex } \\
\text { acts } \\
\text { covered }\end{array}$ & $\begin{array}{l}\text { Condoms } \\
\text { potentially } \\
\text { available } \\
\text { (millions) }\end{array}$ & $\begin{array}{l}\% \text { of all } \\
\text { FSW sex } \\
\text { acts } \\
\text { covered }\end{array}$ & $\begin{array}{l}\text { Condoms } \\
\text { potentially } \\
\text { available } \\
\text { (millions) }\end{array}$ & $\begin{array}{l}\% \text { of all } \\
\text { FSW sex } \\
\text { acts } \\
\text { covered }\end{array}$ & $\begin{array}{l}\text { Condoms } \\
\text { potentially } \\
\text { available } \\
\text { (millions) }\end{array}$ & $\begin{array}{l}\% \text { of all } \\
\text { FSW sex } \\
\text { acts } \\
\text { covered }\end{array}$ & $\begin{array}{l}\text { Condoms } \\
\text { potentially } \\
\text { available } \\
\text { (millions) }\end{array}$ & $\begin{array}{l}\% \text { of all } \\
\text { FSW sex } \\
\text { acts } \\
\text { covered }\end{array}$ \\
\hline $\begin{array}{l}\text { 1. If all available condoms } \\
\text { used by FSWs }\end{array}$ & 7.73 & 35.6 & 8.36 & 38.5 & 12.27 & 56.6 & 18.45 & 85.1 & 20.85 & 96.1 \\
\hline $\begin{array}{l}\text { 2. If some condoms used } \\
\text { for family planning }\end{array}$ & 5.23 & 24.1 & 5.86 & 27.0 & 9.78 & 45.1 & 15.96 & 73.6 & 18.35 & 84.6 \\
\hline $\begin{array}{l}\text { 4. If only programme condoms } \\
\text { used by FSWs }\end{array}$ & 0.64 & 3.0 & 1.27 & 5.90 & 5.72 & 26.4 & 10.93 & 50.4 & 12.16 & 56.1 \\
\hline
\end{tabular}




\section{Key messages}

This is one of the first times that comprehensive free condom distribution data, socially marketed condom data and private sector condom sales data, coupled with detailed estimates of female sex worker (FSW) sexual activity, have been used to estimate possible FSW condom use rates.

- Compared to other estimates, condom use in 2004, before the start of the Avahan programme, must of necessity have been very low, even if in the unlikely event all commercially available condoms were purchased for FSW sex.

- Data on condom availability can be a useful tool for triangulation with other available data, such as self-reported condom use.

Many of the potential problems were associated with trying to count sex acts with non-commercial partners, but as these constituted a minority of overall sex acts the possible errors are unlikely to be significant. The assumptions made about condoms used for family planning and other non-FSW sex in each district may not be entirely accurate. In particular, condom sales in Bangalore, a modern cosmopolitan city, may be higher than the proportion we allocated based only on the size of the sexually active population. However, they are the best estimates possible with the data available. Another potential limitation is that sex worker partnership patterns may not follow a normal distribution as a minority of FSWs account for the majority of sex acts. Furthermore, each district seems to have its own pattern of sex work-for example, sex workers in Bellary report double the number of clients in a week than do sex workers in Bangalore and Mysore. These issues are beyond the scope of this paper. However, more detailed analysis and modelling of these dynamics at a district level, with better data on condom sales, would be useful in determining how well the programme overall is responding to need.

A better understanding of what reported behavioural data actually measure is crucial for examining changes in behaviour and evaluating programme impact. Our findings suggest that data on condom availability can be useful for triangulation with other available data and for estimating condom use. Measuring condom distribution in relation to need is also a good programme metric per se, since it measures the 'condom gap'. At the very least, programme managers are able to see that a programme with a large condom gap may have insufficient coverage, inadequate condom distribution methods or limited behaviour change.

More research on client behaviour and condom preferences, or implementation of a sex worker diary study, would add much needed data to the findings of this study. In settings where good quality programme condom data and commercial sales data are available, as well as details of sex worker behaviour, replication of this methodology would provide more evidence of its utility.

Contributors $\mathrm{JB}$ conceived the idea for the paper, managed the analysis and wrote the manuscript. SM, JFB, MA and BMR assisted with study design and assisted with revisions of the paper. SV and SR assisted with data collection and analysis and reviewed the manuscript.

Funding This research was funded by the Bill \& Melinda Gates Foundation. The views expressed herein are those of the authors and do not necessarily reflect the official policy or position of the Bill \& Melinda Gates Foundation.

Competing interests None.
Ethics approval This study was approved by the ethics committees of the University of Manitoba, Centre Hospitalier Affilié Universitaire de Québec and St John's Medical College.

Provenance and peer review Not commissioned; externally peer reviewed.

\section{REFERENCES}

1. Moses S, Blanchard JF, Kang H, et al. AIDS in South Asia: understanding and responding to a heterogeneous epidemic: Washington: The World Bank, 2006.

2. Nagelkerke NJD, Jha P, Vlas SJ, et al. Modelling HIV/AIDS epidemics in Botswana and India: impact of interventions to prevent transmission. Bull World Health Organ 2002;80:89-96.

3. Williams JR, Foss AM, Vickerman $P$, et al. What is the achievable effectiveness of the India AIDS Initiative intervention among female sex workers under target coverage? Model projections from southern India. Sex Transm Infect 2006;82:372-80.

4. Chandrasekaran P, Dallabetta G, Loo V, et al. Evaluation design for large-scale HIV prevention programmes: the case of Avahan, the India AIDS initiative. AIDS 2008;22 (Suppl 5):S1-15.

5. Avahan. The India AIDS initiative: the business of HIV prevention at scale. New Delhi, India: Bill \& Melinda Gates Foundation, 2008.

6. Blanchard JF, Bhattacharjee P, Kumaran S, et al. Concepts and strategies for scaling up focused prevention for sex workers in India. Sex Transm Infect 2008;84(Suppl 2): ii19-23.

7. Hanck SE, Blankenship KM, Irwin KS, et al. Assessment of self-reported sexual behavior and condom use among female sex workers in India using a polling box approach: a preliminary report. Sex Transm Dis 2008;35:489-94.

8. Turner CF, Miller HG. Zenilman's anomaly reconsidered: fallible reports, ceteris paribus, and other hypotheses. Sex Transm Dis 1997;24:522-7.

9. Zenilman JM, Weisman CS, Rompalo AM, et al. Condom use to prevent incident STDs: the validity of self-reported condom use. Sex Transm Dis 1995;22:15-21.

10. Meekers D, Van Rossem R. Explaining inconsistencies between data on condom use and condom sales. BMC Health Serv Res 2005:5:5

11. Office of Registrar General and Census Commissioner India. Census of India http://censusindia.gov.in/vital_statistics/Vital_Rates/Vital_rates.aspx laccessed 23 May 2009). 2009.

12. International Institute for Population Sciences (IIPS), Macro International. National family health survey (NFHS-3), 2005-6: Karnataka: Mumbai: IIPS, 2008.

13. Family Health International. Behavioral Surveillance Surveys: Guidelines for repeated behavioral surveys in populations at risk of HIV. HIV/AIDS Prevention and care department, Family Health International, Arlington, USA, 2000.

14. Ramakrishnanan L, Gautam A, Goswami P, et al. Programme coverage, condom use and STI treatment among FSWs in a large scale HIV prevention programme: Results from cross-sectional surveys in 22 districts in southern India. Sex Transm Infect 2010;86(Suppl 1):i62-8.

15. Ramesh BM, Beattie T, Shajy I, et al. Changes in risk behaviours and prevalence of sexually transmitted infections following STI HIV preventive interventions among female sex workers in five districts in Karnataka state, south India. Sex Transm Infect 2010;86(Suppl 1):i17-24.

16. Karnataka Health Promotion Trust. CMIS report. Bangalore, India, 2007.

17. Avahan. Use it or lose it: how Avahan used data to shape it HIV prevention efforts in India. New Delhi, India: Bill \& Melinda Gates Foundation, 2008.

18. Rajaram S, Sangameshwar BM, Jaychandran AA, et al. HIV and ST/s in Belgaum district, Karnataka, India. CHARME Working Paper No.1. Bangalore, India: CHARME Project, 2008.

19. Rajaram S, Sangameshwar BM, Jayachandran AA, et al. HIV and STIs in Bellary district, Karnataka, India. CHARME Working Paper No. 3. Bangalore, India: CHARME Project, 2009.

20. Sangameshwar BM, Pradeep BS, Rajaram S, et al. HIV and ST/s in Mysore district, Karnataka, India. CHARME Working Paper No. 2. Bangalore, India: CHARME Project, 2008.

21. Goyal RS. Availability and wastage of free distributed condoms in India. 15th International conference on AIDS. Bangkok, Thailand, 2004.

22. Karnataka Health Promotion Trust, University of Manitoba. Polling booth survey: measuring behaviour change among FSWs in Karnataka. Bangalore, India: KHPT, 2007.

23. Catania JA, Gibson DR, Chitwood DD, et al. Methodological problems in AIDS behavioral research: influences on measurement error and participation bias in studies of sexual behavior. Psychol Bull 1990;108:339-62.

24. Lowndes CM, Jayachandran AA, Pradeep BS, et al. Higher levels of HIV-related risky behaviour reported in polling booth surveys compared to face-to-face interviews in a general population survey in Mysore district, Karnataka state, Southern India. 17th Biennial Meeting of the ISSTDR, Abstract P-339 (Poster). Seattle, USA, 2007.

25. Geraldo N, Labbé AC, Meda H, et al. Condom use in Cotonou and Porto Novo (Bénin): how different are self-reports by female sex workers (FSW) and by their clients? 15th Annual Congress of the International Society for Sexually Transmitted Diseases Research. Ottawa, Canada, 2003.

26. Cohen DA, Farley TA. Social marketing of condoms is great, but we need more free condoms. Lancet 2004:364:13-14. 